Original Research Paper

\title{
Pengolahan Eceng Gondok (Eichornia crassipes) Menjadi Pupuk Organik di Kelurahan Panji Sari Kecamatan Praya, Kabupaten Lombok Tengah
}

\author{
I Dewa Made Alit Karyawan', Adji Darmawan Azmi ${ }^{1}$, Khusnul Khatimah ${ }^{1}$, Ragil Tri Wibowo², Willy \\ Santika Dewi ${ }^{2}$, Intan Permatasari ${ }^{3}$, Rizki Nurhidayah ${ }^{3}$, Suci Mulyati Ramdhani ${ }^{4}$, Safira Monica \\ Nuryuliana $^{4}$, Lalu Haerul Abdulloh ${ }^{5}$, Lale Sundari Djolo Puri ${ }^{6}$, Mia Nila Firdaus ${ }^{7}$ A. Battania \\ Damayani $^{8}$ \\ ${ }^{1}$ Fakultas Teknik Universitas Mataram, Mataram, Indonesia; \\ ${ }^{2}$ Fakultas Keguruan dan Ilmu Pendidikan Universitas Mataram, Mataram, Indonesia; \\ ${ }^{3}$ Fakultas Ekonomi dan Bisnis Universitas Mataram, Mataram, Indonesia; \\ ${ }^{4}$ Fakultas Pertanian Universitas Mataram, Mataram, Indonesia; \\ ${ }^{5}$ Fakultas Perternakan Universitas Mataram, Mataram, Indonesia; \\ ${ }^{6}$ Fakultas Hukum Universitas Mataram, Mataram, Indonesia; \\ ${ }^{8}$ Fakultas Teknologi Pangan Universitas Mataram, Mataram, Indonesia.
}

https://doi.org/10.29303/jpmpi.v3i2.1431

Sitasi: Karyawan, I. D. M. A., Azmi, A. D., Khatimah, K., Wibowo, R. T., Dewi, W. S., Permatasari, I., Nurhidayah, R., Ramdhani, S. M., Nuryuliana, S. M., Abdulloh, L. H., Puri, L. S. D., Firdaus, M. N \& Damayani, A. B. (2022). Pengolahan Eceng Gondok (Eichornia crassipes) Menjadi Pupuk Organik di Kelurahan Panji Sari Kecamatan Praya, Kabupaten Lombok Tengah. Jurnal Pengabdian Magister Pendidikan IPA, 5(1).

Article history

Received: 21 Januari 2022

Revised: 30 Januari 2022

Accepted: 27 Februari 2022

*Corresponding Author: I

Dewa Made Alit

Karyawan, Fakultas Teknik, Universitas Mataram, Mataram, Indonesia

Email: dewaalit@unram.ac.id

\begin{abstract}
Panjisari merupakan desa yang terletak di sekitar genangan dan daerah aliran sungai Bendungan Batujai. Di bendungan ini, gulma eceng gondok (Eichhornia crassipes) tumbuh pesat yang berdampak pada pemanfaatan perairan dan pendangkalan waduk. Salah satu upaya untuk mengatasi masalah tersebut adalah dengan memanfaatkan eceng gondok sebagai pupuk. Pupuk organik dari eceng gondok mampu memperbaiki struktur fisik tanah, meningkatkan ketersediaan unsur hara, dan pertumbuhan vegetatif. Tim KKN menjadikan kegiatan pembuatan pupuk ini sebagai program utama mereka. Program ini dilaksanakan dengan memberikan bantuan kepada kelompok masyarakat mulai Desember 2021 hingga Februari 2022 bertempat di rumah produksi. Proses pembuatannya dimulai dengan persiapan alat, pengambilan bahan (eceng gondok, kotoran sapi dan sekam), pencacahan dan pengeringan, pencampuran dan fermentasi, yang terakhir adalah pengemasan pupuk. Tim KKN berhasil membuat pupuk organik dengan bahan utama eceng gondok dan memberikan edukasi cara membuatnya kepada masyarakat. Selain itu, produk pupuk organik eceng gondok dapat dipasarkan secara luas, sehingga menciptakan peluang usaha baru untuk meningkatkan perekonomian masyarakat Panjisari.
\end{abstract}

Keywords: Panjisari, eceng gondok, pupuk organik

pesatnya pertumbuhan gulma air seperti eceng gondok. Pada suatu bendungan (waduk) gulma air akan menimbulkan dampak negatif berupa gangguan terhadap pemanfaatan perairan yaitu mempercepat pendangkalan, menyumbat saluran irigasi, memperbesar kehilangan air melalui proses 
evapotranspirasi, mempersulit transportasi perairan, menurunkan hasil perikanan air tawar.

Kelurahan Panjisari adalah kelurahan yang terletak di sekitar genangan Bendungan Batujai. Luas wilayah kelurahan ini sebesar 118.33 Ha yang terdiri dari 6 lingkungan yaitu Lingkungan Harapan Baru, Lingkungan Bukal Malang, Lingkungan Kemulah, Lingkungan Darul Falah Selatan, Lingkungan Darul Falah Utara, Lingkungan Gelondong. Mata pencaharian di kelurahan Panjisari sebagian besar di dominasi oleh petani, buruh tani, peternak, dan nelayan ikan air tawar. Memiliki lahan pertanian seluas $170,5 \mathrm{Ha}$ dan lahan perkebunan seluas 210 Ha. Terletak di area genangan bendungan batujai, kelurahan Panjisari tidak luput dari pencemaran eceng gondok, khususnya daerah aliran sungai yang melintasi lingkungan Bukal Malang, Kemulah dan Gelondong.

Eceng gondok (Eichornia crassipes) adalah tumbuhan air terbesar yang hidup mengapung bebas (floating plants) yang ditemukan pertama kali pada air tergenang di daerah aliran sungai Amazon di Brasil pada tahun 1824 oleh Karl von Martius (Pieterse dalam Dinges, 1982). Eceng gondok merupakan gulma perairan yang memiliki tingkat perkembangbiakan yang cukup tinggi yakni dalam waktu 52 hari, setiap satu batang eceng gondok mampu menghasilkan tanaman baru seluas $1 \mathrm{~m}^{2}$. Gambar 1 menunjukkan hamparan eceng gondok yang tumbuh di Bendungan Batujai.

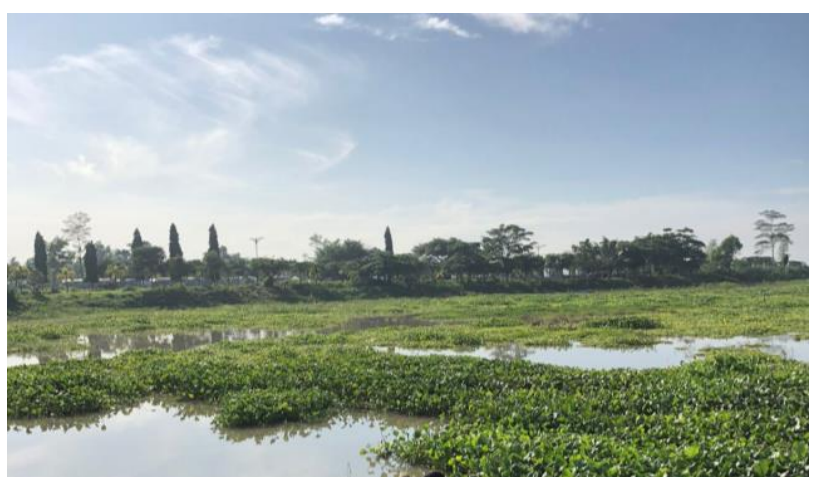

Gambar 1. Eceng gondok di Bendungan Batujai

Hasil penelitian di India menunjukkan bahwa eceng gondok dapat dijadikan sebagai sumber bahan organik alternative, eceng gondok yang masih segar mengandung 95,5\% air, 3,5\% bahan organik, $0,04 \%$ nitrogen, $1 \%$ abu; $0,06 \%$ pospor dan $0,2 \%$ kalium, sedangkan bahan kering eceng gondok menmghasilkan $75,8 \%$ bahan organik;
1,5\% nitrogen; $24,2 \%$ abu. Dengan demikian bahan organik dan unsur hara yang tinggi yang terkandung pada eceng gondok dapat dijadikan sebagai alternatif sumber pupuk kompos.

Enceng gondok memiliki potensi besar sebagai sumber bahan organik. Hasil dekomposisi enceng gondok dapat digunakan sebagai pupuk hijau atau sebagai kompos yang dapat memperbaiki kualitas tanah (Ndimele, 2012). Sabagai pupuk hijau, enceng gondok dapat diaplikasikan dengan cara dibenamkan ke tanah atau digunakan sebagai mulsa (Mujere, 2016).

Pengolahan eceng gondok melalui teknologi pengomposan (dekomposisi) menghasilkan produk berupa bahan organik yang lebih halus dan telah terdekomposisi sempurna. Proses pengomposan itu sendiri merupakan proses hayati yang melibatkan aktivitas mikroorganisme antara lain bakteri, fungi dan protozoa. Penelitian terdahulu menunjukkan bahwa penggunaan eceng gondok sebagai sumber bahan organik mampu memperbaiki struktur fisik tanah, meningkatkan ketersediaan unsur hara, dan pertumbuhan vegetatif.

Pembuatan kompos menjadi alternatif pemanfaatan enceng gondok yang mampu mendatangkan pendapatan. Selain itu, pembuatan kompos atau pupuk organik menggunakan proses produksi dengan modal yang rendah (Mujere, 2016). Sehingga dapat menciptakan usaha baru yang bermanfaat untuk meningkatkan taraf ekonomi dan enterpreneur masyarakat sekitar kelurahan Panjisari.

\section{Metode}

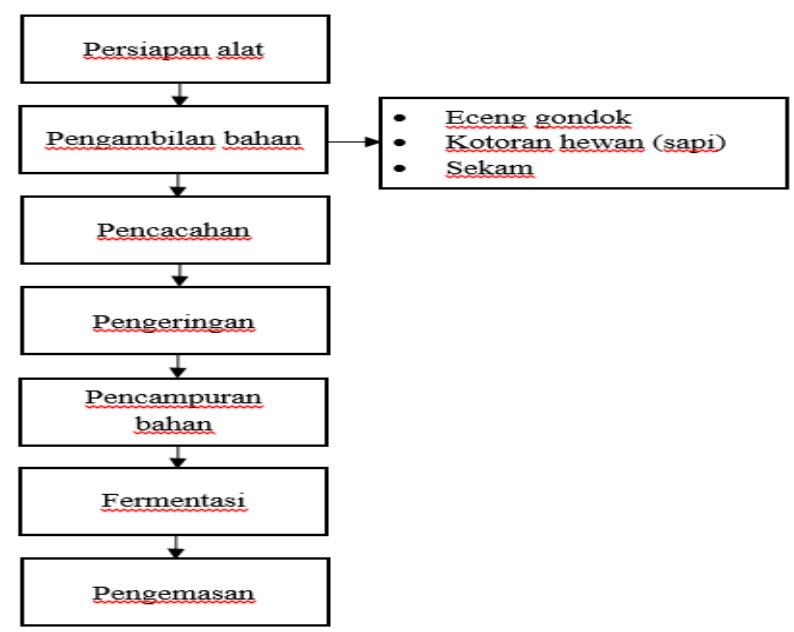

Gambar 2. Proses pembuatan pupuk organik 
Pelaksanaan pengabdian Kuliah Kerja Nyata (KKN) ini dilakukan di rumah produksi di Lingkungan Bukal Malang, Kelurahan Panjisari, Kecamatan Praya, Kabupaten Lombok Tengah selama bulan Desember 2021 sampai Februari 2022.

Langkah-langkah proses pembuatan pupuk organik eceng gondok ditunjukkan pada Gambar 2.

\section{Hasil dan Pembahasan}

Pada kegiatan Kuliah Kerja Nyata (KKN) dilakukan upaya untuk mengurangi pencemaran oleh eceng gondok. Hal itu dapat dilakukan dengan mengubah eceng gondok menjadi pupuk organik atau kompos yang berfungsi untuk memperbaiki struktur tanah yang telah rusak dan meningkatkan unsur hara tanah agar menjadi lebih subur.

Berikut tahapan pembuatan pupuk organik eceng gondok:

\section{a. Persiapan alat}

- Pembuatan rumah produksi

Rumah produksi yang dibangun bersama masyarakat (Gambar 3) digunakan sebagai tempat untuk mengolah dan menyimpan pupuk organik eceng gondok hasil produksi.

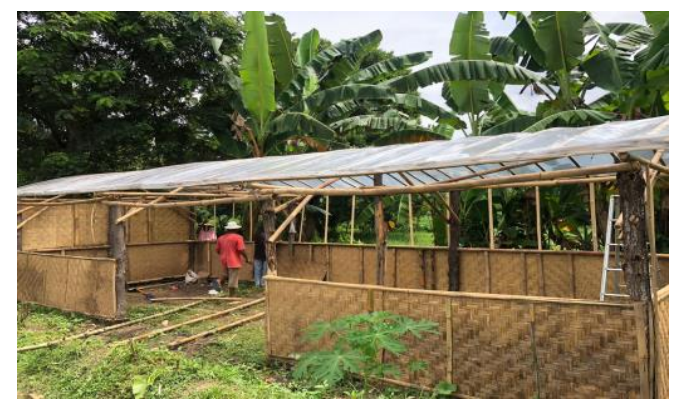

Gambar 3. Rumah produksi

- Alat yang digunakan

Alat yang digunakan untuk membuat pupuk organik eceng gondok adalah corong, ember, tabung semprot, mesin pencacah, dan alat ukur pH (Gambar 4).

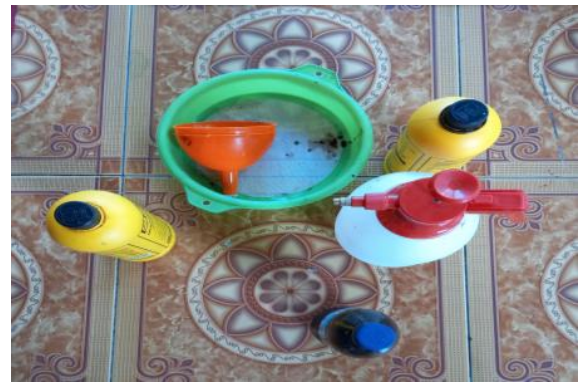

Gambar 4. Alat yang digunakan

\section{b. Pengambilan bahan}

Bahan-bahan yang digunakan untuk produksi pupuk kompos eceng gondok yaitu eceng gondok yang diambil langsung dari bendungan batujai dan daerah aliran sungai lingkungan Bukal Malang (Gambar 5). Pengambilan kotoran sapi langsung dari kandang peternak yang ada di daerah kelurahan Panji Sari, sekam padi, molasses, dan dekomposer EM4.

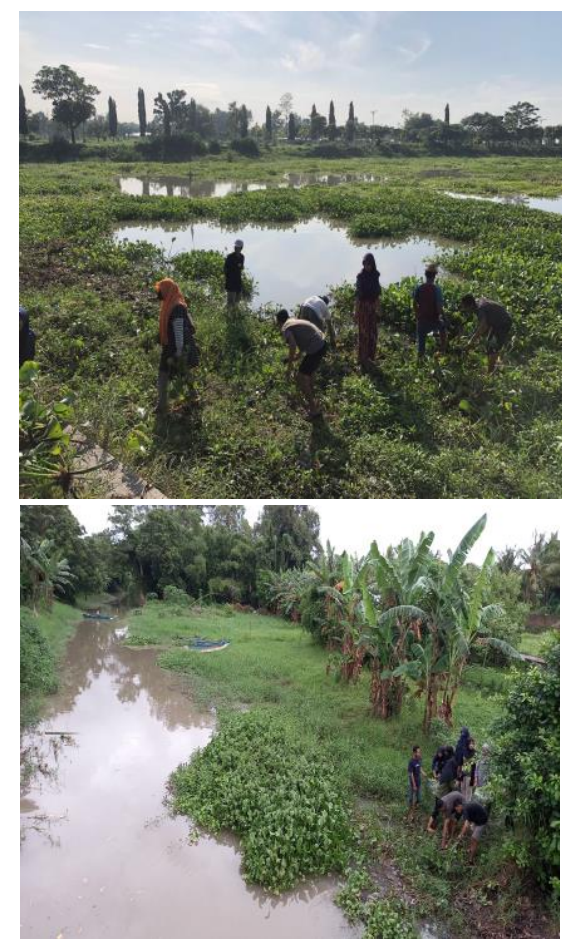

Gambar 5. Pengambilan eceng gondok

\section{c. Pencacahan}

Pencacahan eceng gondok dilakukan dengan mesin pencacah agar ukuran eceng gondok menjadi lebih kecil sehingga dihasilkan serat 
eceng gondok yang mudah untuk terurai. Lihat Gambar 6.

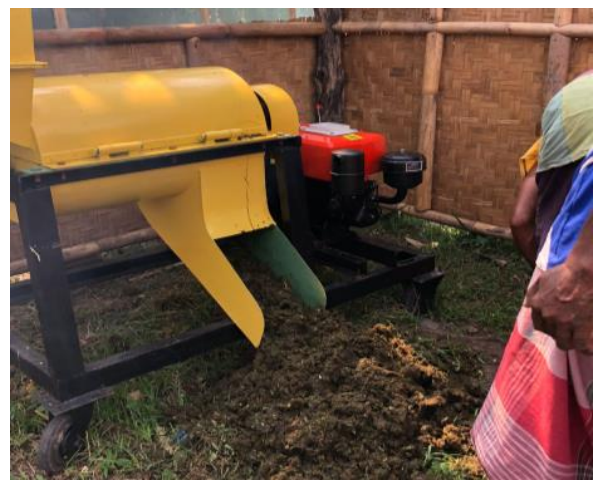

Gambar 6. Pencacahan eceng gondok

\section{d. Pengeringan}

Pengeringan dilakukan dengan menjemur eceng gondok hasil pencacahan dan menjemur kotoran sapi (Gambar 7) agar mencapai kadar air yang telah ditentukan yaitu harus kurang dari $25 \%-30 \%$.

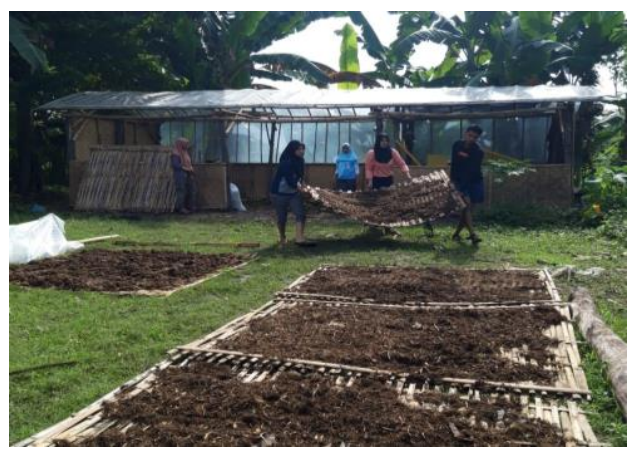

Gambar 7. Penjemuran eceng gondok dan kotoran hewan

\section{e. Pencampuran bahan}

Bahan-bahan yang telah mencapai kadar air yang cukup kemudian dicampur dengan perbandingan-perbandingan yang telah ditentukan yaitu $50 \%$ eceng gondok, $40 \%$ kotoran sapi, $5 \%$ sekam dan $5 \%$ abu sekam. Kemudian disiram dengan larutan EM4 dan molasses di setiap tumpukan lapisan. Gambar 8, meunjukkan proses pencampuran bahan untuk membuat pupuk organik.

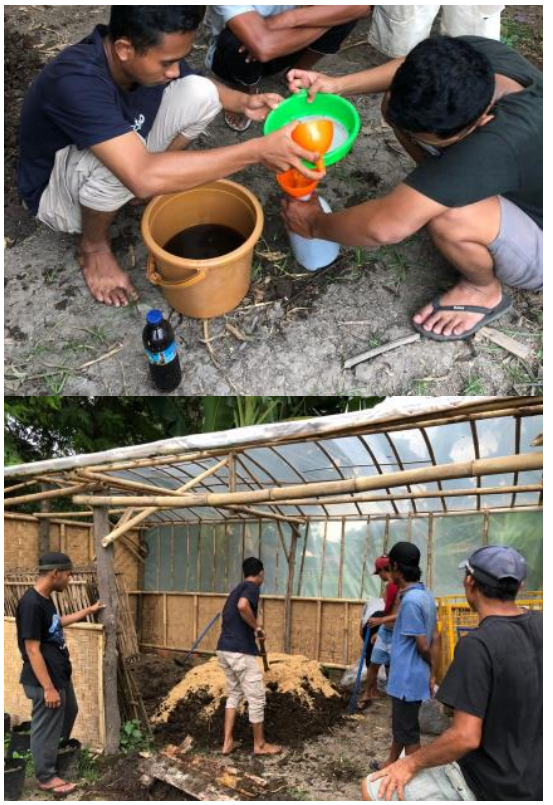

Gambar 8. Pencampuran seluruh bahan

\section{f. Fermentasi}

Fermentasi atau dekomposisi ditunjukkan dalam Gambar 9, dilakukan minimal 14 hari, dan dilakukan pengecekan secara berkala untuk mengetahui suhu dan kondisi pupuk. Suhu akhir pupuk harus normal yaitu $27^{\circ} \mathrm{C}$ $30^{\circ} \mathrm{C}$. Sedangkan $\mathrm{pH}$ akhir harus netral yaitu 5-7.

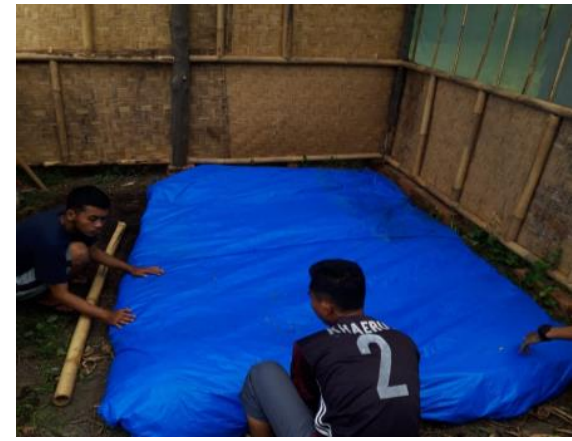

Gambar 9. Fermentasi produk pupuk organic

\section{g. Pengemasan}

Jika pupuk organik telah terurai dengan sempurna dan mencapai suhu yang telah ditentukan maka dapat dilakukan pengemasan agar menarik dan mudah untuk dipasarkan pada konsumen. Hasil pengemasan produk pupuk organik, ditunjukkan dalam Gambar 10. 


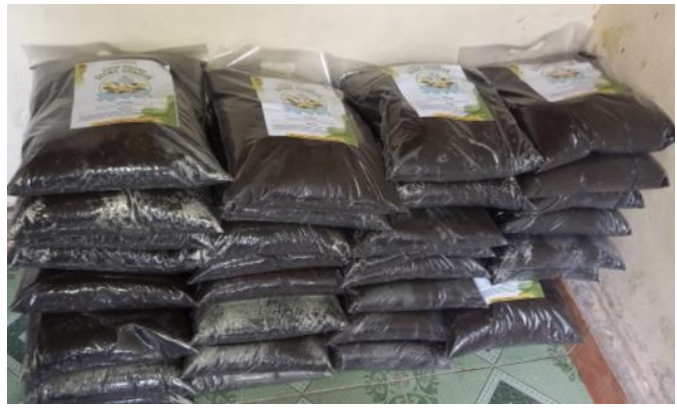

Gambar 10. Produk pupuk organik eceng gondok

\section{h. Pemasaran}

\section{- Sosialisasi produk}

Sosialisasi dilakukan sebagai upaya untuk mengenalkan produk hasil KKN yaitu pupuk organik eceng gondok Selain untuk mensosialisasikan tentang cara pengolahan eceng gondok menjadi pupuk organik (lihat Gambar 11).

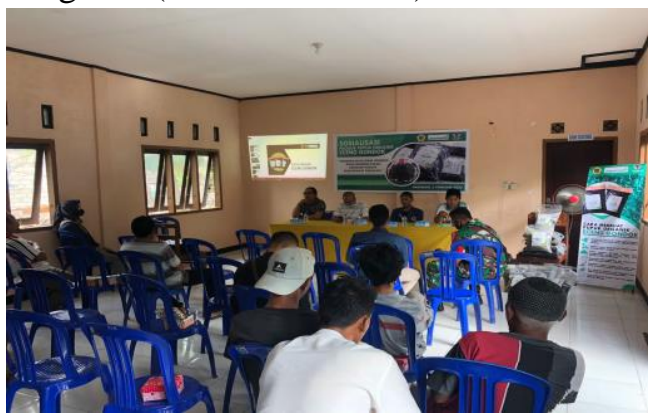

Gambar 11. Sosialisasi produk

- Penjualan produk

Pupuk yang telah diproduksi kemudian dipasarkan kepada masyarakat dengan harga yang terjangkau yaitu Rp 10.000 dalam kemasan $3 \mathrm{~kg}$, seperti pada Gambar 12.

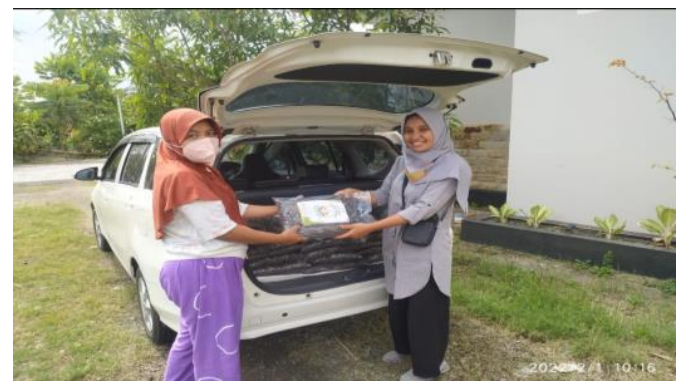

Gambar 12.Pengantaran produk ke konsumen

Berdasarkan kegitan KKN yang telah dilaksanakan dapat disimpulkan bahwa eceng gondok dapat dimanfaatkan menjadi pupuk organik atau pupuk kompos yang berfungsi untuk meningkatkan unsur hara tanah dan menambah kesuburan tanah. Pupuk organik eceng gondok diproduksi menggunakan bahan-bahan yang merupakan sumber daya dari kelurahan Panjisari. Produk dapat dipasarkan sehingga menciptakan lapangan usaha baru dan meningkatkan perekonomian di kelurahan Panjisari. Pupuk organik eceng gondok dijual dengan harga yang terjangkau sehingga masyarakat dapat dengan mudah membelinya.

\section{Ucapan Terima Kasih}

Kami mengucapkan terimakasih kepada semua pihak yang membantu dalam pengolahan pupuk organik eceng gondok yaitu kelompok masyarakat (POKMAS) Panjisari, dan mesyarakat kelurahan Panjisari khususnya lingkungan Bukal Malang.

\section{Daftar Pustaka}

Dinges, R, 1982. Natural Systems for Water Pollution Control. Van Nostrand Reinhold Environment Engineering Series. VNR Company. New York, Cincinnati, Toronto, Melbourne.

Ismail, Moh Sarif., Iqrima Sstaddal, \& Sjahril Botutihe. (2020). Pembuatan Pupuk Organik Berbahan Eceng Gondok (Eichornia crassipes) Menggunakan Alat Pencacah Limbah Organik. Jurnal Teknologi Pertanian Gorontalo (JTPG)

Mujere, N. (2016). Water Hyacinth: Characteristics, Problems, Control Options, and Beneficial Uses. In A. E. McKeown \& G. Bugyi (Eds.), Impact of Water Pollution on Human Health and Environmental Sustainability (pp. 343361). IGI Global. https://doi.org/10.4018/978-1-4666-95597.ch015

Ndimele, P. E. (2012). The effects of water hyacinth (Eichhornia crassipes [Mart.] solms) infestation on the physicochemistry, 
nutrient and heavy metal content of Badagry creek and Ologe lagoon, Lagos, Nigeria. Journal of Environmental Science and Technology, 5(2), 128-136.

Prihatiningtyas, Evi., Asysyifa, \& Susilawati. (2020). Pemanfaatan Eceng Gondok (Eichornia crassipes) Untuk Mengurangi Pencemaran Air dan Meningkatkan Ekonomi Masyarakat Desa Tungkaran. Universitas Lambung Mangkurat, Banjarmasin.

Sittadewi, Eythalia Hanggari. (2007). Pengolahan Bahan Organik Eceng Gondok Menjadi Media Tumbuh Untuk Mendukung Pertanian Organik. Jurnal Teknik Lingkungan, 8(3), 229-234

Yunindanova, Mercy Bientri., Supriyono, \& Bayu Setya Hertanto. (2020). Pengolahan Gulma Invansif Eceng Gondok Menjadi Pupuk Organik Layak Pasar Sebagai Solusi Masalah Rawa Pening. Journal of Community Empowering and Services, 4(2), 78-87. 